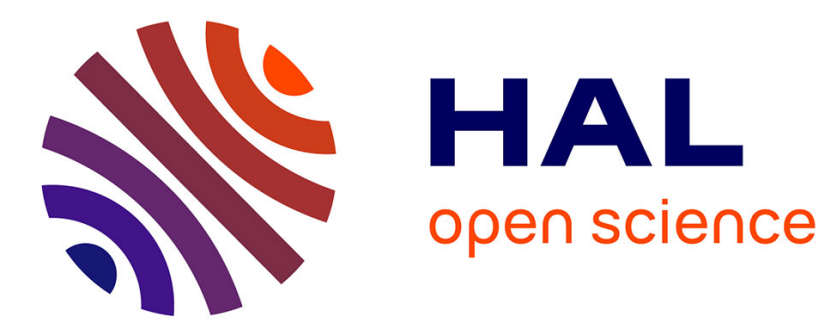

\title{
Latent toxoplasma infection in real-world schizophrenia: Results from the national FACE-SZ cohort
}

\author{
G. Fond, L. Boyer, F. Schürhoff, F. Berna, O. Godin, E. Bulzacka, M.
}

Andrianarisoa, L. Brunel, Bruno Aouizerate, D. Capdevielle, et al.

\section{- To cite this version:}

G. Fond, L. Boyer, F. Schürhoff, F. Berna, O. Godin, et al.. Latent toxoplasma infection in realworld schizophrenia: Results from the national FACE-SZ cohort. Schizophrenia Research, 2018, 201, pp.373-380. 10.1016/j.schres.2018.05.007 . hal-02094446

\section{HAL Id: hal-02094446 \\ https://hal.sorbonne-universite.fr/hal-02094446}

Submitted on 9 Apr 2019

HAL is a multi-disciplinary open access archive for the deposit and dissemination of scientific research documents, whether they are published or not. The documents may come from teaching and research institutions in France or abroad, or from public or private research centers.
L'archive ouverte pluridisciplinaire HAL, est destinée au dépôt et à la diffusion de documents scientifiques de niveau recherche, publiés ou non, émanant des établissements d'enseignement et de recherche français ou étrangers, des laboratoires publics ou privés. 
Latent Toxoplasma infection in real-world schizophrenia: results from the national FACE-SZ cohort.

Running title: Toxoplasma gondii in schizophrenia

Fond $G^{a, c}$, MD PhD, Boyer $L^{\mathrm{a}, \mathrm{c}}$, MD PhD, Schürhoff $\mathrm{F}^{\mathrm{a}, \mathrm{b}}$, MD PhD, Berna $\mathrm{F}^{\mathrm{a}, \mathrm{e}}$, MD PhD, Godin $\mathrm{O}^{\mathrm{a}, \mathrm{p}}$, PhD, Bulzacka $\mathrm{E}^{\mathrm{a}, \mathrm{b}}$, Msc, Andrianarisoa $\mathrm{M}^{\mathrm{a}, \mathrm{b}}$, MD, Brunel $\mathrm{L}^{\mathrm{a}, \mathrm{b}}$, Msc, Aouizerate $\mathbf{B}^{\mathrm{a}, \mathrm{d}, \mathrm{n}}$, MD PhD, Capdevielle $\mathrm{D}^{\mathrm{a}, \mathrm{f}}$, MD PhD, Chereau $\mathbf{I}^{\mathrm{a}, \mathrm{g}}$, MD, Coulon $\mathrm{N}^{\mathrm{a}, \mathrm{b}}$, MD, D'Amato $T^{\mathrm{a}, \mathrm{h}}$, MD PhD, Dubertret $\mathrm{C}^{\mathrm{a}, \mathrm{i}}$, MD PhD, Dubreucq $\mathbf{J}^{\mathrm{a}, \mathrm{j}}$, MD, Faget $\mathbf{C}^{\mathrm{a}, \mathrm{c}}$, MD, Lançon $C^{a, c}$, MD PhD, Leignier $\mathrm{S}^{\mathrm{a}, \mathrm{j}}$, MD, Mallet $\mathrm{J}^{\mathrm{a}, \mathrm{i}}$, MD PhD, Misdrahi $\mathrm{D}^{\mathrm{a}, \mathrm{d}, \mathrm{o}}$, MD, Passerieux $\mathrm{C}^{\mathrm{a}, \mathrm{l}}$, MD PhD, Rey $\mathrm{R}^{\mathrm{a}, \mathrm{h}}$, MD, Schandrin $\mathrm{A}^{\mathrm{a}, \mathrm{f}}$, MD, Urbach $\mathbf{M}^{\mathrm{a}, \mathrm{l}}$, MD, Vidailhet $\mathbf{P}^{\mathrm{e}}$, MD PhD, Llorca PM ${ }^{\mathrm{a}, \mathrm{g}}$, MD PhD, Leboyer $\mathbf{M}^{\mathrm{a}, \mathrm{b}}$, MD PhD

And the FACE-SZ (FondaMental Academic Centers of Expertise for Schizophrenia) group*

${ }^{\text {a }}$ Fondation FondaMental, Créteil, France

${ }^{\mathrm{b}}$ INSERM U955, équipe de psychiatrie translationnelle, Créteil, France, Université Paris-Est Créteil, DHU Pe-PSY, Pôle de Psychiatrie des Hôpitaux Universitaires H Mondor, Créteil, France

${ }^{c}$ Aix-Marseille Univ, Faculté de Médecine - Secteur Timone, EA 3279: CEReSS -Centre d'Etude et de Recherche sur les Services de Santé et la Qualité de vie, 27 Boulevard Jean Moulin, 13005 Marseille, France

${ }^{\mathrm{d}}$ Centre Hospitalier Charles Perrens, F-33076 Bordeaux, France; Université de Bordeaux

e Hôpitaux Universitaires de Strasbourg, Université de Strasbourg, INSERM U1114, Fédération de Médecine Translationnelle de Strasbourg, Strasbourg, France

f Service Universitaire de Psychiatrie Adulte, Hôpital la Colombière, CHRU Montpellier, Université Montpellier 1, Inserm 1061, Montpellier, France. 
g CMP B, CHU, EA 7280 Faculté de Médecine, Université d'Auvergne, BP 6963003 Clermont-Ferrand Cedex 1, France.

h INSERM U1028, CNRS UMR5292, Centre de Recherche en Neurosciences de Lyon, Université Claude Bernard Lyon 1, Equipe PSYR2, Centre Hospitalier Le Vinatier, Pole Est, 95 bd Pinel, BP 30039, 69678 Bron Cedex, France.

i AP-HP, Department of Psychiatry, Louis Mourier Hospital, Colombes, Inserm U894, Université Paris Diderot, Sorbonne Paris Cité, Faculté de médecine, France.

${ }^{\text {j }}$ Centre Référent de Réhabilitation Psychosociale, CH Alpes Isère, Grenoble, France.

${ }^{1}$ Centre Hospitalier de Versailles, Service de psychiatrie et d'addictologie adulte, Le Chesnay, EA 4047 HANDIReSP, UFR des Sciences de la Santé Simone Veil, Université Versailles Saint-Quentin-en-Yvelines, Versailles, France

${ }^{\mathrm{n}}$ INRA, NutriNeuro, University of Bordeaux, U1286 F-33076 Bordeaux, France

${ }^{\circ}$ CNRS UMR 5287-INCIA

p Sorbonne Universités, UPMC Univ Paris 06, UMR_S 1136, Institut Pierre Louis d'Epidémiologie et de Santé Publique, F-75013, Paris, France, INSERM, UMR_S 1136, Institut Pierre Louis d'Epidémiologie et de Santé Publique, F-75013, Paris, France

\section{* Correspondence should be sent to: Dr Guillaume FOND}

Aix-Marseille Univ, Faculté de Médecine - Secteur Timone, EA 3279: CEReSS -Centre d'Etude et de Recherche sur les Services de Santé et la Qualité de vie, 27 Boulevard Jean Moulin, 13005 Marseille, France

Tel: (33 6681022 58), e-mail: guillaume.fond@ap-hm.fr

Word count: 3638

*Members of the FACE-SCZ Group 


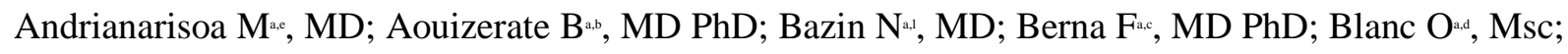

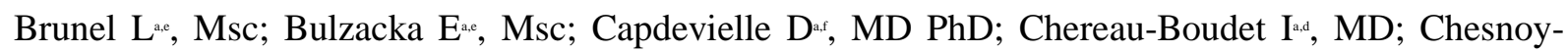

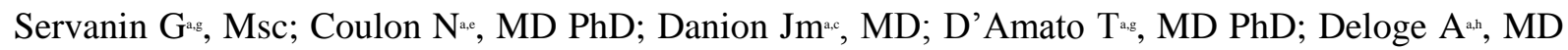

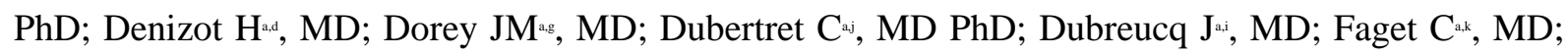
Fluttaz $\mathrm{C}^{\mathrm{ai}}$, Msc; Fond Ga, MD; Fonteneau Sa, Msc; Gabayet Fai, Msc; Giraud-Baro E ${ }^{a i}$, MD; Jarroir $\mathrm{M}^{\mathrm{a}}$, MsC; Leignier S Lacelle $\mathrm{D}^{\mathrm{a}}$, Msc; Lançon $\mathrm{C}^{\mathrm{a} k}$, MD PhD; Laouamri $\mathrm{H}^{\mathrm{a}}, \mathrm{Msc}$; ;Leboyer $\mathrm{M}^{\mathrm{a}}$,, $\mathrm{MD}$ PhD; Le Gloahec Tae, Msc; Le Strat Y ${ }^{a j}$, MD PhD; Llorca ${ }^{a d} P M$, MD PhD; Mallet J ${ }^{a j}$, MD; Metairie $E^{a k}$,

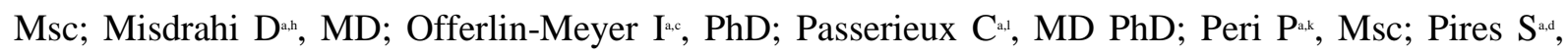

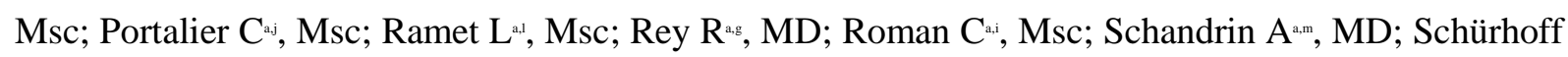

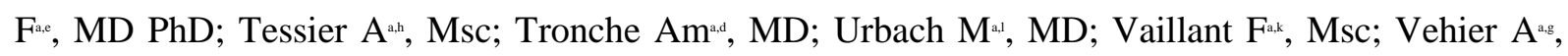

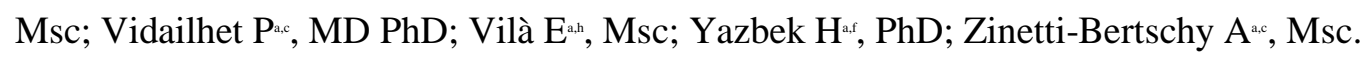

\section{${ }^{a}$ Fondation Fondamental}

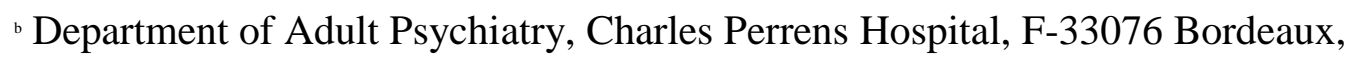
France; Laboratory of Nutrition and Integrative Neurobiology (UMR INRA 1286), University of Bordeaux, France

• Strasbourg University Hospital, University of Strasbourg, INSERM U1114, Federation of Translational Psychiatry, Strasbourg, France

`Clermont-Ferrand University Hospital, EA 7280 Auvergne University, BP 6963003 Clermont-Ferrand Cedex 1, France

`INSERM U955, Translational Psychiatry Team, DHU Pe-PSY, Centre Expert Schizophrénie, Pôle de Psychiatrie et d'Addictologie des Hôpitaux Universitaires Henri Mondor, Paris Est University, 40 rue de Mesly, 94000 Créteil, France

${ }^{`}$ University Department of Adult Psychiatry, La Colombiere Hospital, CHU Montpellier, University of Montpellier 1, Inserm 1061, Montpellier, France sUniversity Claude Bernard Lyon 1, Le Vinatier Hospital Pole Est BP 30039 - 95 bd Pinel 69678 BRON Cedex, France 
${ }^{\text {h }}$ Department of Adult Psychiatry, Charles Perrens Hospital, F-33076 Bordeaux; University of Bordeaux, CNRS UMR 5287-INCIA, Bordeaux, France

i Psychosocial Rehabilitation Reference Center, Alpes Isère Hospital, Grenoble, France j AP-HP, Department of Psychiatry, Louis Mourier Hospital, Colombes, Inserm U894 Université Paris Diderot, Sorbonne Paris Cité, Faculté de médecine, France ${ }^{k}$ Department of Psychiatry (AP-HM), Sainte-Marguerite University Hospital, Marseille, France

' Department of Adult Psychiatry, Versailles Hospital, Le Chesnay, France ; HandiRESP Laboratory, EA4047, UFR Health Sciences Simone Veil, Université de Versailles SaintQuentin-En-Yvelines, Montigny-le-Bretonneux, France

${ }^{\mathrm{m}}$ Department of Adult Psychiatry, University Hospital of Nimes, France. 


\begin{abstract}
Objective: Latent Toxoplasma infection has been associated with widespread brain immune activation, increased blood brain barrier permeability, neural disruption, increased dopamine release in dopaminergic neurons, with NMDA activation and with schizophrenia (SZ) onset risk. Toxoplasma has been suggested to be a source of chronic low-grade inflammation and this inflammation has been associated with cognitive impairment in SZ. The objective of the present study were (i) to determine if latent Toxoplasma infection was associated with specific clinical features in stabilized SZ subjects, with cognitive impairment and with increased low-grade peripheral inflammation and (ii) to determine if Treatments with AntiToxoplasmic Activity (TATA) were associated with improved outcomes in subjects with latent Toxoplasma infection.
\end{abstract}

Methods: A comprehensive 2 daylong clinical and neuropsychological battery was administered in 250 SZ subjects included between 2015 and 2017 in the national FondaMental Expert Center (FACE-SZ) Cohort. Solid phase-enzyme microplate immunoassay methods were used to measure IgG class of antibodies to T. gondii in blood sample. Latent Toxoplasma infection was defined by $\mathrm{T}$. gondii $\operatorname{IgG}$ ratio $\geq 0.8$, equivalent to $\geq 10$ international units. Chronic peripheral inflammation was defined by highly sensitive $\mathrm{C}$ reactive protein blood level $\geq 3 \mathrm{mg} / \mathrm{L}$.

Results: Latent Toxoplasma infection has been found in 184 (73.6\%) of this national multicentric sample. In the multivariate analyses, latent Toxoplasma infection has been significantly associated with higher PANSS negative (aOR=1.1 [1.1-1.1], p=0.04) and excitement subscores $(\mathrm{aOR}=1.3$ [1.1-1.6], $\mathrm{p}=0.01)$, with two specific symptoms (i.e., reference delusion $(\mathrm{aOR}=3.6$ [1.2-10.6] $\mathrm{p}=0.01)$ and alogia $(\mathrm{aOR}=16.7$ [2.0-134.7], $\mathrm{p}=0.008))$ and with chronic low-grade peripheral inflammation $(27.2 \%$ vs. $7.6 \%$, aOR=3.8 [1.4-10.3], $\mathrm{p}=0.004$ ). Extrapyramidal symptoms remained significantly associated with latent Toxoplasma infection. On the opposite, no significant association of latent Toxoplasma infection with age, gender, age at SZ onset, suicide behavior or cognitive deficits has been found in these models (all $\mathrm{p}>0.05$ ). TATA were associated with lower depressive symptoms ( $\mathrm{aOR}=0.8[0.7-0.9], \mathrm{p}=0.01)$, and with lower rates of chronic peripheral inflammation $(20.9 \%$ vs. $48.6 \%, a O R=3.5$ [1.5-7.9], $\mathrm{p}=0.003)$ but not with higher cognitive scores $(\mathrm{p}>0.05)$. 
Conclusion: The present findings suggest that Toxoplasma is almost 3 times more frequent in SZ population compared to general population in France. The potential cerebral underpinnings of the association of latent Toxoplasma infection and the above-mentioned outcomes have been discussed. Future studies should confirm that TATA may be effective to reduce Toxoplasma-associated depressive symptoms and low-grade peripheral inflammation.

Keywords: Toxoplasma gondii, schizophrenia, inflammation, symptoms, treatment 


\section{Introduction}

Schizophrenia (SZ) has been strongly associated with latent Toxoplasma infection, even before the onset of the illness (Sutterland et al., 2015). Toxoplasmosis is the most common protozoa parasite infecting one third of the global human population (Kim and Weiss, 2008). This intracellular parasite alters the expression of host cell genes (including brain cells) and persists in the form of cysts. These cysts can reactivate and release parasites by neo-spread throughout the host, depending on his/her immune status (Carruthers, 2002). T. gondii's neurotropism and its impact on dopamine pathway have been demonstrated (Prandovszky et al., 2011) and dopamine disturbances may be associated with psychotic or mood episodes (Abi-Dargham, 2014). Toxoplasma infection has also been suggested to active cross-reactions with NMDA receptors that are involved in SZ onset and maintenance as well as with disruption of neuronal circuits and cognitive deficits (Lucchese, 2017). Toxoplasma infection has also been associated with the complement C1Q activation, which can cause synapse pruning that has been suggested to be involved in SZ onset (Xiao et al., 2016). Exposure to Toxoplasma has been associated with increased blood-brain barrier permeability in SZ subjects (Kannan et al., 2017) and with substantial and widespread immune activation including increased $\mathrm{C}$ reactive protein (Tomasik et al., 2016).

From a clinical point of view, latent Toxoplasma infection has been associated with older age of SZ onset (Esshili et al., 2016), treatment resistance (Vlatkovic et al., 2017), more severe illness course (Celik et al., 2015) and lower functioning (Esshili et al., 2016). Latent Toxoplasma infection has been associated with negative symptoms in one study (Esshili et al., 2016), but not in one another (Karabulut et al., 2015). Conflicting results have also been found on the association between latent Toxoplasma infection and suicide attempt, with some studies suggesting it as a potential risk factor for suicide (Dickerson et al., 2017; Okusaga et al., 2016, 2011) vs. one other as a protective factor (Hsu et al., 2014). One other major finding in this field was the discovery that several antipsychotic drugs, and mood stabilizers such as valproate, have anti-toxoplasmic activity (Treatments with Anti-Toxoplasmic Activity, TATA) (Fond et al., 2013). However, it remains unclear whether the administration of TATA may be associated with better clinical outcomes in SZ subjects with latent Toxoplasma infection (Fond et al., 2015). Latent Toxoplasma infection may therefore play a major role in pathogenesis but also on clinical presentation of SZ patients and response to treatment. 
The objectives of the present study were to determine (i) if latent Toxoplasma infection was associated with some clinical features (including illness characteristics, psychotic and mood severity, suicide, cognitive deficits and remission under treatment) and with increased peripheral inflammation in a national sample of stabilized SZ subjects and (ii) if TATA were associated with better clinical outcomes in subjects with latent Toxoplasma infection. Our hypotheses were that latent Toxoplasma infection was associated with higher levels of psychotic symptomatology under treatment, with lower cognitive scores, with higher suicidal behavior, with increased low-grade peripheral inflammation and that TATA was associated with better outcomes in subjects with latent Toxoplasma infection.

\section{Population and methods}

\section{Study design}

The FACE-SZ (FondaMental Academic Centers of Expertise for Schizophrenia) is a national cohort of 10 Schizophrenia Expert Centers, set up by a scientific cooperation foundation in France, the FondaMental Foundation (www.fondation-fondamental.org) (for all details, see (Schürhoff et al., 2015)).

\section{Study population}

Consecutive clinically stable patients (defined by no hospitalization and no treatment changes during the 8 weeks before evaluation) with a DSM-IV-TR diagnosis of schizophrenia or schizoaffective disorder were consecutively included in the study.

\section{Data collected}

Patients were interviewed by members of the specialized multidisciplinary team of the Expert Center. Information about education level and illness duration was recorded. Current daily tobacco smoking was self-reported. Ongoing psychotropic treatment was recorded as well as other medication. The Simpson and Angus Scale (SAS) is a 10-item scale used in the evaluation of clinical and research practices to assess DIP. One item measures gait, six items measure stiffness and three items measure tremor, salivation and palpebral reflex respectively. This scale is validated and among those most used in individuals with schizophrenia in naturalistic conditions (Knol et al., 2010). Anti-toxoplasmic activity was defined according to in vitro definition (Fond et al., 2015, 2013). Cyamemazine, fluphenazine, haloperidol, levomepromazine, loxapine, paliperidone, risperidone, thioridazine, zuclopenthixol, valproate 
were considered as TATA ("TATA+") while amisulpride, aripiprazole, carbamazepine, clozapine, lamotrigine, lithium carbonate, olanzapine, quetiapine, tiapride were considered as having no or negligible antitoxoplasmic activity ("TATA-"). TATA+/ TATA- groups were defined according to the current treatment, given that patients were stabilized for more than 8 weeks at the inclusion in the study.

National Adult Reading Test (Nelson and O'Connell, 1978) provides an estimate of premorbid intellectual ability. French version of the NART was used in our analysis (Mackinnon and Mulligan, 2005).

Wechsler Adult Intelligence Scale - 3rd Edition (Wechsler, 2008) provides a measure of general intellectual function in older adolescents and adults. Seven subtest short form (Ryan and Ward, 1999) was used to estimate the Full Scale IQ (FSIQ), Verbal IQ (VIQ) and Performance IQ (PIQ), and allowed exploration of the following cognitive areas: Picture Completion (visual exploration and detail perception), Digit-Symbol Coding (visual-motor coordination, motor and mental speed), Similarities (abstract verbal reasoning), Arithmetic (mathematical problem solving), Matrix Reasoning (nonverbal abstract problem solving, inductive spatial reasoning), Digit span (attention, working memory, mental control), Information (general information acquired from culture, semantic memory). An additional subtest, Letter-Number Sequencing was administered, which along with two other primary subtests, Digit Span and Arithmetic, allowed the calculation of a Working Memory Index (WMI) (auditory working memory and mental control).

Trail Making Test (Reitan, 1958) reflects the control of attention, visual exploration, speed and mental flexibility. The subject is asked to connect, by making pencil lines, encircled numbers randomly arranged on a page in proper order (Part A) and encircled numbers and letters in alternating order (Part B). A French version of the normative data was used (Godefroy, 2008).

California Verbal Learning Test (Delis et al., 2000) is designed to measure verbal learning and memory using a multiple-trial list-learning task. The examiner reads the word list and records the patient's oral responses verbatim in the order in which they are given. Learning efficiency, strategies, interference management and learning bias are measured. A French version of the task was used in this study (Poitrenaud et al., 2007). 
Doors test (Baddeley et al., 1994) is a visual recognition memory test in which participants view photographs of 12 doors for 3 seconds each. Immediately thereafter, participants are presented with 12 arrays of four doors each, and are asked to identify the door from the previous list. In the second part new photographs of doors are displayed, but the recognition stimuli are rather similar to the key list.

The Continuous Performance Test - Identical Pairs (CPT-IP) is a computerized measure of sustained, focused attention or vigilance. This version is a part of MCCB-Matrics Consensus Cognitive Battery and involves monitoring a series of multiple digits and responding with a button press each time that two stimuli in a row are identical (Nuechterlein et al., 2008)

\section{Serological analysis}

Solid phase-enzyme microplate immunoassay methods were used to measure IgG class of antibodies to T. gondii in blood sample. The results were quantified by calculating a ratio between the reactivity of the samples and a standard sample run on each microplate. Latent Toxoplasma infection was defined by $\mathrm{T}$. gondii $\operatorname{IgG}$ ratio $\geq 0.8$, equivalent to $\geq 10$ international units. All samples were analysed under code by the laboratory not having access to diagnostic or clinical information. As the clinical evaluation and the serological analysis were separated in time and location, the clinical evaluation and the serological analysis were both blinded.

\section{Ethical concerns}

The study was carried out in accordance with ethical principles for medical research involving humans (WMA, Declaration of Helsinki). The assessment protocol was approved by the relevant ethical review board (CPP-Ile de France IX, January 18th, 2010). All data were collected anonymously. As this study include data coming from regular care assessments, a non-opposition form was signed by all participants.

\section{Statistical analysis}

Socio-demographics, clinical characteristics, addictive behaviour, neuropsychological scores and treatments are presented using measures of means and dispersion (standard deviation) for continuous data and frequency distribution for categorical variables. The data 
were examined for normal distribution with the Shapiro-Wilk test and for homogeneity of variance with the Levene test. Comparisons between individuals with or without latent Toxoplasma infection, regarding demographic, clinical characteristics were performed using the chi-square test for categorical variables. Continuous variables were analysed with Student t-tests for normally distributed data and in case of normality violation, additional MannWhitney tests were performed to confirm the result. The same analyses were carried out in subjects with latent Toxoplasma infection only to compare those being administered TATA+ vs. TATA- at the time of the evaluation.

Multiple logistic regressions were then performed to confirm the association between symptomatology (i.e., severity of symptoms based on PANSS scores and type of symptoms based on SCID psychotic symptoms), cognition, peripheral inflammation and latent Toxoplasma infection, after adjusting for the main confounding factors based on univariate analysis (i.e., variables with $\mathrm{p}$ values $<0.20$ ), namely age, gender and extra pyramidal symptoms. Each association was tested in separate models to consider multicollinearity and overfitting problems. Age and gender were forced in each model. To test our hypotheses on the link between symptomatology and latent Toxoplasma infection, we performed four models exploring (i) the link with the severity of symptoms (i.e., PANSS subscores) (model 1) (ii) the link with the type of symptoms (i.e., SCID psychotic symptoms) (model 2) (iii) the link with peripheral inflammation (model 3). PANSS total score was only included in model 3 to avoid colinearity with PANSS subscores and SCID psychotic symptoms in the first two models.

As the rationale for assessing the association between TATA and respectively clinical and cognitive outcomes and peripheral inflammation was the inhibition of Toxoplasma reactivation by TATA, only toxopositive subjects with fulfilled data for current psychotropic treatment $(\mathrm{N}=145)$ were included in the further analyses. To explore the associations with TATA in subjects with latent Toxoplasma infection, only two models were carried out (one on specific symptoms and one on low-grade peripheral inflammation), given that no significant association between TATA and general psychotic symptomatology (PANSS subscores) was found in univariate analyses (with $\mathrm{p}>0.2$ ). The final models included odds ratios and $95 \%$ confidence intervals. This study was a confirmatory analysis. No correction for multiple testing has therefore been carried out, which is consistent with recommendations (Bender and Lange, 2001). Analyses were conducted using SPSS 17.0 software (SPSS Inc., Chicago, IL). All statistical tests were two-tailed, with $\alpha$ level set at 0.05 . 


\section{Results}

Overall, 250 community-dwelling stabilized SZ were consecutively recruited between 2015 and 2017 in the Schizophrenia Expert Center Network. The mean age was 32.0+/-8.6 years, 184 (73.6\%) were male, the mean age at illness onset was 21.8+/-6.7 years and the mean PANSS score was 71.1+/-19.4. Overall, 184 patients $(73.6 \%)$ were classified in the group with latent Toxoplasma infection.

In the multivariate analyses, latent Toxoplasma infection has been significantly associated with higher PANSS negative $(\mathrm{OR}=1.1$ [1.1-1.1], $\mathrm{p}=0.04)$ and excitement subscores $(\mathrm{OR}=1.3$ [1.1-1.6], $\mathrm{p}=0.01)$, with two specific symptoms (i.e., reference delusion $(\mathrm{OR}=3.6$ [1.2-10.6] $\mathrm{p}=0.01)$ and alogia $(\mathrm{OR}=16.7$ [2.0-134.7], $\mathrm{p}=0.008))$ and with higher rates of lowgrade peripheral inflammation $(27.2 \%$ vs. $7.6 \%, \mathrm{aOR}=3.8$ [1.4-10.3], $\mathrm{p}=0.004)$ (table 1). Extrapyramidal symptoms remained significantly associated with latent Toxoplasma infection in each model. On the opposite, no significant association of latent Toxoplasma infection with age, gender, age at SZ onset, suicide behavior or cognitive deficits has been found in these models (all p>0.05) (for cognition, see supplementary material).

TATA were associated with lower depressive symptoms ( $\mathrm{aOR}=0.8[0.7-0.9], \mathrm{p}=0.01)$, and with lower rates of chronic peripheral inflammation $(20.9 \%$ vs. $48.6 \%$, aOR=3.5 [1.57.9], $\mathrm{p}=0.003$ ) (table 2) but not with higher cognitive scores (all $\mathrm{p}>0.05$, see table 2 and supplementary table for cognition).

\section{Discussion}

Altogether, the present findings may be summarized as follows: in a national sample of community-dwelling stabilized SZ subjects mean aged 32 years, $73.6 \%$ were found with latent Toxoplasma infection. Latent Toxoplasma infection has been significantly associated with higher negative and excitement subscores, with reference delusion and alogia, with increased extrapyramidal symptoms and strongly with chronic low-grade peripheral inflammation. On the opposite, no significant association of latent Toxoplasma infection with age, gender, age at SZ onset, suicide behavior or cognitive deficits has been found. TATA have been associated with lower depressive symptoms in toxopositive patients as well as with lower peripheral low-grade inflammation. 
The first result of this study is the extremely high prevalence of latent Toxoplasma infection (almost three quarter) in a mean-aged population of 32 years, while Toxoplasma prevalence has been estimated to decrease to $27 \%$ in 2020 in the mean-aged 40 years French population (Nogareda et al., 2014). In other words, latent Toxoplasma infection has been found to be almost 3 times higher in this non-selected national sample of SZ subjects that is on average 8 years younger than the general population, while the rate of latent Toxoplasma infection increased throughout life. These results are consistent with those of a recent metaanalysis suggesting that the over-representation of Toxoplasma in SZ populations was found even before illness onset (Sutterland et al., 2015) and those of another French study carried out earlier in a different monocentric sample (Fond et al., 2015).

Latent Toxoplasma infection has been associated with negative symptoms and excited symptoms, and specifically with delusion reference and alogia, independently of sociodemographic characteristics, treatments and comorbidities. This is consistent with previous studies suggesting that Toxoplasma was associated with treatment resistance (Vlatkovic et al., 2017) and more specifically with increased negative symptoms (Esshili et al., 2016). The absence of association between Toxoplasma and negative symptoms in Karabulut et al. study was probably due to statistical power lack $(\mathrm{N}=85)$ (Karabulut et al., 2015). The present results have highlighted for the first time that latent Toxoplasma infection was highly associated with alogia. The large IC of the odd ratio [2-134] is due to the small number of SZ subjects with alogia in the toxonegative group (only one (1.7\%) vs. 57 (36.3\%) in the toxopositive group). These results suggest that alogia may be highly specific of toxopositive SZ subjects. Alogia is a negative symptom defined as a poverty of speech that can be seen in SZ as well as in dementia and intellectual disability. It can be brought on by frontostriatal dysfunction, which causes a degradation of the semantic store (Joyce et al., 1996). A recent study has demonstrated that the reduction in speech was a strong predictor of psychosis onset in subjects at risk for psychosis (Corcoran et al., 2018). The present results suggest that latent Toxoplasma infection may cause particular brain dysfunctions related to langage abnormalities, and the strong odd ratio $(36.3 \%$ in toxopositive vs. $1.7 \%$ in toxonegative subjects, $\mathrm{aOR}=16.7, \mathrm{p}<0.0001$ ) suggests that alogia is quite specific of $\mathrm{SZ}$ subjects with latent Toxoplasma infection (only one toxonegative patient was classified with alogia). Latent Toxoplasma infection has been associated for the first time with the delusion of reference in the present study. Delusion of reference has been specifically associated with the dysregulation of the mesolimbic dopaminergic system (Heinz and Schlagenhauf, 2010), with altered brain functional connectivity (Larivière et al., 2017) and gray matter 
abnormalities in the caudate head (Tao et al., 2015). The cysts of latent Toxoplasma have been located in amygdala and ventral striatum, two areas that have been associated with delusion of reference in schizophrenia (Menon et al., 2011). Alogia and delusion of reference may therefore be seen as the result of a general brain dysfunction (Girard et al., 2017) that may be specifically related to microglial activation (Laskaris et al., 2016), a microglial activation that may be due to Toxoplasma infection.

Another major result of the present study is the association of latent Toxoplasma infection with increased extrapyramidal symptoms, while no difference in daily dose of antipsychotic treatments has been found between the groups. This suggests that Toxoplasma dopaminergic brain modulation may be responsible of increased extrapyramidal symptoms under antipsychotic treatment. This association has never been explored to date and should be confirmed in other SZ populations.

Latent Toxoplasma infection has not been significantly associated with history of suicide attempt in the present sample. This is not consistent with a previous study finding lower rates of suicide attempt in a sample of 99 Iranian SZ subjects (Ansari-Lari et al., 2017). In the Sugden et al. birth cohort study of 837 Americans, there was only a trend between Toxo infection and suicide attempt (Sugden et al., 2016). In the Okusaga et al. study including 340 toxopositive American SZ subjects, suicide attempt was found to be significantly increased only in those with increased kynurenic acid levels (Okusaga et al., 2016). A meta-analysis is needed to determine whether or not latent Toxoplasma infection is associated with increased suicide risk and the factors that may modulate this association (including age at Toxoplasma infection, Toxoplasma strain and serointensity, ethnicity).

No significant association between Toxoplasma infection and cognitive deficits has been found in the present study. This is consistent with the results in a previous preliminary study with fewer cognitive tests (Sugden et al., 2016) and in a study carried out in a non-SZ population (Shehata et al., 2016). This may be explained by the multiple confounding factors and the intrinsic effect of schizophrenia. In other words, toxo-associated cognitive deficits may be more pronounced in non-SZ populations compared to SZ because SZ subjects have multiple other causes of impaired cognition (including genetic factors, lifestyle, other treatments and comorbidities).

No association between Toxoplasma status and age at SZ onset has been found in the present study, which is consistent with previous results (Ansari-Lari et al., 2017; Fond et al., 2015) but inconsistent with others suggesting that latent Toxoplasma infection was associated with older age at SZ onset (Esshili et al., 2016). The association between Toxoplasma and 
older age at SZ onset was only found in males in the Esshili et al. study, which may explain the discrepancy with the present results. As this study was carried out in Tunisia, these discrepancies may also be explained by different Toxoplasma prevalence and genotypes across countries and different mean ages at Toxoplasma infection.

TATA has been associated with lower depressive symptoms but not with higher cognitive scores in the present sample of toxopositive SZ subjects. This is consistent with one of our previous study that suggested that TATA was associated with lower lifetime number of depressive episodes in patients with bipolar disorders (Fond et al., 2015). Moreover, TATA has been associated with lower rates of chronic peripheral inflammation in subjects with latent Toxoplasma infection in the present sample, and peripheral inflammation has been associated with depression in schizophrenia (Faugere et al., 2018). TATA have been described to inhibit the parasite's life cycle in vitro, and particularly its reactivation that may induce peripheral inflammation. This result may open the path to new strategies to address low-grade peripheral inflammation in SZ subjects. Given that this study was cross-sectional, no data on lifetime TATA treatment prescription was available. Future studies should determine if administering TATA in first-episode SZ subjects with latent Toxoplasma infection may improve the prognosis and prevent chronic low-grade peripheral inflammation associated with latent Toxoplasma infection. It may be hypothesized that the absence of significant association between latent Toxoplasma and increased suicide behavior may also be due to TATA administration in the present sample.

Strengths. The 2 daylong evaluation, the comprehensive neuropsychological test battery, the standardized evaluation, the national multicentric recruitment, the assessment of treatments effect and the multiple confounding factors taken into account in analyses may be mentioned in the strengths of the present work. Specific psychotic symptoms, cognition, peripheral inflammation and TATA have not been explored in previous studies on Toxoplasma in SZ subjects; this is therefore a strength of the present work.

Limits and future directions. The Toxoplasma strain, the serointensity (IgG blood level) and IgG avidity have not been reported in the present study. Only one diagnostic tool has been used, which is a limit of the present work. As Toxoplasma infection is usually asymptomatic, it has not been possible to measure the age at Toxoplasma infection, which may have impacted clinical characteristics. It may reasonably be hypothesized that an infection during early childhood may have more severe consequences on brain functioning, as suggested in an animal model of brain Toxoplasma infection (Kannan et al., 2016). IgG avidity is only a proxy to evaluate the most recent Toxoplasma infection/reactivation and is 
not provided in routine practice. While most of the Toxoplasma infections in France are due to the genotype 2 strain (less virulent than the 1), it may be hypothesized that SZ subjects may have been exposed to other strains, which may explain the increased risk for SZ onset in these subjects (Xiao and Yolken, 2015). The ALOX12 gene (a gene coding for the arachidonate 12lipooxygenase) has been associated with immune response to Toxoplasma infection in human cells, it may explain the discrepancies found between the present study and the literature (Witola et al., 2014). Future studies should include these parameters that may modulate the outcomes associated with latent Toxoplasma infection in SZ subjects. The population in the Expert centers may represent the more severe cases of schizophrenia, however many patients are referred for treatment management, diagnostic issues, the mean age was 32 years and illness characteristics (age at illness onset of 21.8 years, tobacco smoking prevalence of 52\%) suggests that the present sample may be representative of the French SZ population. The analysis on TATA was carried out in a smaller sample of toxopositive subjects with treatment data $(\mathrm{N}=145)$, these results may lack of statistical power and should be replicated in larger samples.

\section{Conclusion}

The present findings suggest that latent Toxoplasma infection is 3 times more frequent in SZ subjects compared to the general French population, and that latent Toxoplasma infection is associated with specific psychotic features and with peripheral inflammation in these subjects. Future studies should confirm in longitudinal analyses if administering TATA treatments may improve depression, peripheral inflammation and other outcomes in SZ.

\section{Acknowledgments and funding source}

\section{Collaborators :}

Andrianarisoa $\mathrm{M}^{\mathrm{a} e}$, MD; Aouizerate $\mathrm{B}^{\mathrm{ab}}$, MD PhD; Bazin N ${ }^{\mathrm{a}}$, MD; Berna Fac, MD PhD; Blanc $\mathrm{O}^{a, d}$, Msc; Brunel L La, Msc; Bulzacka E Ese, Msc; Capdevielle Dar, MD PhD; Chereau-Boudet I Ia, MD; ChesnoyServanin $\mathrm{G}^{\mathrm{as}}$, Msc; Coulon Nac, MD PhD; Danion Jmª, MD; D’Amato T ${ }^{\mathrm{a}}$,, MD PhD; Deloge $\mathrm{A}^{\mathrm{ath}}$, MD PhD; Denizot $\mathrm{H}^{a, d}$, MD; Dorey JM ${ }^{a s}$, MD; Dubertret $C^{a j}$, MD PhD; Dubreucq J ${ }^{a i}$, MD; Faget $C^{a k}$, MD; Fluttaz C $C^{a i}$, Msc; Fond G ${ }^{a}$, MD; Fonteneau Sa, Msc; Gabayet Fai, Msc; Giraud-Baro E Eai, MD; Jarroir $\mathrm{M}^{a+1}$, MsC; Leignier S Lacelle D ${ }^{a\lrcorner}$, Msc; Lançon $C^{a k}$, MD PhD; Laouamri $\mathrm{H}^{a}$, Msc; ;Leboyer $\mathrm{M}^{\mathrm{a} e}$, MD 
PhD; Le Gloahec T Ta, Msc; Le Strat $Y^{a j}$, MD PhD; Llorca ${ }^{a d} P M, M D P h ;$ Mallet J ${ }^{a j}$, MD; Metairie $E^{a k}$,

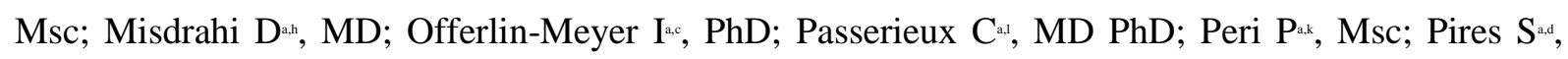

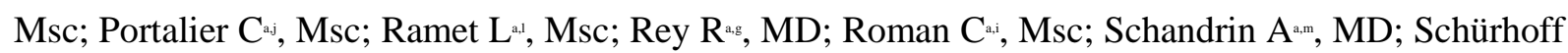

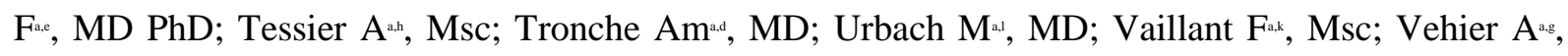

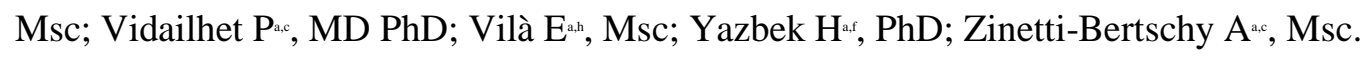

${ }^{a}$ Fondation Fondamental

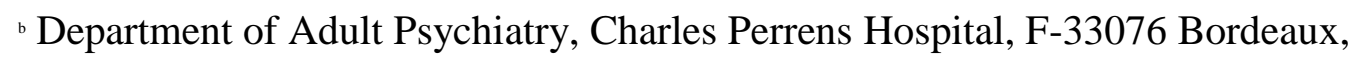
France; Laboratory of Nutrition and Integrative Neurobiology (UMR INRA 1286), University of Bordeaux, France

· Strasbourg University Hospital, University of Strasbourg, INSERM U1114, Federation of Translational Psychiatry, Strasbourg, France

¿ Clermont-Ferrand University Hospital, EA 7280 Auvergne University, BP 6963003

Clermont-Ferrand Cedex 1, France

- INSERM U955, Translational Psychiatry Team, DHU Pe-PSY, Centre Expert

Schizophrénie, Pôle de Psychiatrie et d'Addictologie des Hôpitaux Universitaires Henri Mondor, Paris Est University, 40 rue de Mesly, 94000 Créteil, France

‘University Department of Adult Psychiatry, La Colombiere Hospital, CHU Montpellier, University of Montpellier 1, Inserm 1061, Montpellier, France

¿University Claude Bernard Lyon 1, Le Vinatier Hospital Pole Est BP 30039 - 95 bd Pinel 69678 BRON Cedex, France

${ }^{\text {n }}$ Department of Adult Psychiatry, Charles Perrens Hospital, F-33076 Bordeaux; University of Bordeaux, CNRS UMR 5287-INCIA, Bordeaux, France

' Psychosocial Rehabilitation Reference Center, Alpes Isère Hospital, Grenoble, France j AP-HP, Department of Psychiatry, Louis Mourier Hospital, Colombes, Inserm U894 Université Paris Diderot, Sorbonne Paris Cité, Faculté de médecine, France 
${ }^{k}$ Department of Psychiatry (AP-HM), Sainte-Marguerite University Hospital, Marseille,

France

' Department of Adult Psychiatry, Versailles Hospital, Le Chesnay, France ; HandiRESP

Laboratory, EA4047, UFR Health Sciences Simone Veil, Université de Versailles Saint-

Quentin-En-Yvelines, Montigny-le-Bretonneux, France

${ }^{\mathrm{m}}$ Department of Adult Psychiatry, University Hospital of Nimes, France.

This work was funded by AP-HM (Assistance Publique des Hôpitaux de Marseille), Fondation FondaMental (RTRS Santé Mentale), by the Investissements d'Avenir program managed by the ANR under reference ANR-11-IDEX-0004-02 and ANR-10-COHO-10-01, and by INSERM (Institut National de la Santé et de la Recherche Médicale).

We express all our thanks to the nurses, and to the patients who were included in the present study. We thank Hakim Laouamri, and his team (Stéphane Beaufort, Seif Ben Salem, Karmène Souyris, Victor Barteau and Mohamed Laaidi) for the development of the FACE-SZ computer interface, data management, quality control and regulatory aspects. We thank Lore Brunel for editorial assistance.

\section{Contributors}

Dr Guillaume Fond, Dr Laurent Boyer wrote the manuscript.

All authors designed the study and wrote the protocol.

Dr Guillaume Fond and dr Laurent Boyer managed the statistical analysis.

All authors contributed to and approved the final manuscript.

\section{Conflict of interest.}

The authors report no conflict of interest. 


\section{References}

Abi-Dargham, A., 20I4. Schizophrenia: overview and dopamine dysfunction. J. Clin.

Psychiatry 75, e3 I. https://doi.org// 0.4088/JCP.I3078tx2c

Ansari-Lari, M., Farashbandi, H., Mohammadi, F., 2017. Association of Toxoplasma gondii infection with schizophrenia and its relationship with suicide attempts in these patients.

Trop. Med. Int. Health TM IH 22, I322-1327. https://doi.org/I0.I I I //tmi. 12933

Baddeley, A.D., Emslie, H., Nimmo-Smith, I., 1994. Doors and people: A test of visual and verbal recall and recognition. Thames Valley Test Company.

Bender, R., Lange, S., 200 I. Adjusting for multiple testing-when and how? J. Clin. Epidemiol. 54, 343-349. https://doi.org/10.1016/S0895-4356(00)00314-0

Carruthers, V.B., 2002. Host cell invasion by the opportunistic pathogen Toxoplasma gondii.

Acta Trop. 81, III-122.

Celik, T., Kartalci, S., Aytas, O., Akarsu, G.A., Gozukara, H., Unal, S., 20I5. Association

between latent toxoplasmosis and clinical course of schizophrenia - continuous course of the disease is characteristic for Toxoplasma gondii-infected patients. Folia Parasitol. (Praha) 62. https://doi.org/I0.144I I/fp.2015.015

Corcoran, C.M., Carrillo, F., Fernández-Slezak, D., Bedi, G., Klim, C., Javitt, D.C., Bearden, C.E., Cecchi, G.A., 2018. Prediction of psychosis across protocols and risk cohorts using automated language analysis. World Psychiatry Off. J. World Psychiatr. Assoc. WPA 17, 6775. https://doi.org/10.1002/wps.2049I

Delis, D.C., Kramer, J.H., Kaplan, E., Ober, B.A., 2000. California Verbal Learning Test . San Antonio, TX: The Psychological Corporation. Harcourt Assessment Company.

Dickerson, F., Wilcox, H.C., Adamos, M., Katsafanas, E., Khushalani, S., Origoni, A., Savage, C., Schweinfurth, L., Stallings, C., Sweeney, K., Yolken, R., 20I7. Suicide attempts and markers of immune response in individuals with serious mental illness. J. Psychiatr. Res. 87, 37-43. https://doi.org/I0.1016/j.jpsychires.2016.1 I.0I I

Esshili, A., Thabet, S., Jemli, A., Trifa, F., Mechri, A., Zaafrane, F., Gaha, L., Juckel, G., Babba, H., Bel Hadj Jrad, B., 2016. Toxoplasma gondii infection in schizophrenia and associated clinical features. Psychiatry Res. 245, 327-332. https://doi.org/I0.1016/j.psychres.2016.08.056 Faugere, M., Micoulaud-Franchi, J.-A., Faget-Agius, C., Lançon, C., Cermolacce, M., Richieri, R., 2018. High C-reactive protein levels are associated with depressive symptoms in schizophrenia. J. Affect. Disord. 225, 67I-675. https://doi.org/I0.1016/j.jad.2017.09.004 Fond, G., Boyer, L., Gaman, A., Laouamri, H., Attiba, D., Richard, J.-R., Delavest, M., Houenou, J., Le Corvoisier, P., Charron, D., Krishnamoorthy, R., Oliveira, J., Tamouza, R., Yolken, R., Dickerson, F., Leboyer, M., Hamdani, N., 20I5. Treatment with anti-toxoplasmic activity (TATA) for toxoplasma positive patients with bipolar disorders or schizophrenia: a cross-sectional study. J. Psychiatr. Res. 63, 58-64.

https://doi.org/I0.1016/j.jpsychires.2015.02.0I I

Fond, G., Macgregor, A., Tamouza, R., Hamdani, N., Meary, A., Leboyer, M., Dubremetz, J.F., 2013. Comparative analysis of anti-toxoplasmic activity of antipsychotic drugs and valproate. Eur. Arch. Psychiatry Clin. Neurosci. https://doi.org/10.1007/s00406-0 I3-04I3-4 Girard, T.A., Lakatos, L., Menon, M., 2017. Aberrant modulation of brain activation by emotional valence during self-referential processing among patients with delusions of reference. J. Behav. Ther. Exp. Psychiatry 56, 21-26.

https://doi.org/10.1016/j.jbtep.2016.11.007

Godefroy, O., 2008. Fonctions exécutives et pathologies neurologiques et psychiatriques: évaluation en pratique clinique. Groupe de Boeck.

Heinz, A., Schlagenhauf, F., 20I0. Dopaminergic dysfunction in schizophrenia: salience attribution revisited. Schizophr. Bull. 36, 472-485. https://doi.org//0.1093/schbul/sbq03 I 
Hsu, P.-C., Groer, M., Beckie, T., 2014. New findings: depression, suicide, and Toxoplasma gondii infection. J. Am. Assoc. Nurse Pract. 26, 629-637. https://doi.org/10.1002/23276924.12129

Joyce, E.M., Collinson, S.L., Crichton, P., 1996. Verbal fluency in schizophrenia: relationship with executive function, semantic memory and clinical alogia. Psychol. Med. 26, 39-49. https://doi.org//0.1017/S0033291700033705

Kannan, G., Crawford, J.A., Yang, C., Gressitt, K.L., Ihenatu, C., Krasnova, I.N., Cadet, J.L., Yolken, R.H., Severance, E.G., Pletnikov, M.V., 2016. Anti-NMDA receptor autoantibodies and associated neurobehavioral pathology in mice are dependent on age of first exposure to Toxoplasma gondii. Neurobiol. Dis. 9I, 307-3 I4. https://doi.org//0.1016/j.nbd.2016.03.005 Kannan, G., Gressitt, K.L., Yang, S., Stallings, C.R., Katsafanas, E., Schweinfurth, L.A., Savage, C.L.G., Adamos, M.B., Sweeney, K.M., Origoni, A.E., Khushalani, S., Bahn, S., Leweke, F.M., Dickerson, F.B., Yolken, R.H., Pletnikov, M.V., Severance, E.G., 20I7. Pathogen-mediated NMDA receptor autoimmunity and cellular barrier dysfunction in schizophrenia. Transl. Psychiatry 7, el I86. https://doi.org/10.1038/tp.2017.162

Karabulut, N., Bilgiç, S., Gürok, M.G., Karaboğa, F., 20I5. Is there any role of latent toxoplasmosis in schizophrenia disease? J. Chin. Med. Assoc. JCMA 78, 533-537. https://doi.org/I0.1016/j.jcma.2015.06.007

Kim, K., Weiss, L.M., 2008. Toxoplasma: the next 100years. Microbes Infect. 10, 978-984. Knol, W., Keijsers, C.J.P.W., Jansen, P.A.F., van Marum, R.J., 20I0. Systematic evaluation of rating scales for drug-induced parkinsonism and recommendations for future research. J. Clin. Psychopharmacol. 30, 57-63. https://doi.org/10.1097/JCP.0b0I3e3 I8Ic9/4b3 Larivière, S., Lavigne, K.M., Woodward, T.S., Gerretsen, P., Graff-Guerrero, A., Menon, M., 2017. Altered functional connectivity in brain networks underlying self-referential processing in delusions of reference in schizophrenia. Psychiatry Res. 263, 32-43.

https://doi.org//0.1016/j.pscychresns.2017.03.005

Laskaris, L.E., Di Biase, M.A., Everall, I., Chana, G., Christopoulos, A., Skafidas, E., Cropley, V.L., Pantelis, C., 2016. Microglial activation and progressive brain changes in schizophrenia. Br. J. Pharmacol. 173, 666-680. https://doi.org// 0.1 I I I/bph.13364 Lucchese, G., 2017. From Toxoplasmosis to Schizophrenia via NMDA Dysfunction: Peptide Overlap between Toxoplasma gondii and N-Methyl-d-Aspartate Receptors As a Potential Mechanistic Link. Front. Psychiatry 8, 37. https://doi.org/I0.3389/fpsyt.2017.00037 Mackinnon, A., Mulligan, R., 2005. [The estimation of premorbid intelligence levels in French speakers]. L'Encéphale 3I, 3I-43.

Menon, M., Schmitz, T.W., Anderson, A.K., Graff, A., Korostil, M., Mamo, D., Gerretsen, P., Addington, J., Remington, G., Kapur, S., 20I I. Exploring the neural correlates of delusions of reference. Biol. Psychiatry 70, I I27-I I33. https://doi.org/I0.1016/j.biopsych.201 I.05.037 Nelson, H.E., O'Connell, A., 1978. Dementia: the estimation of premorbid intelligence levels using the New Adult Reading Test. Cortex J. Devoted Study Nerv. Syst. Behav. 14, 234-244. Nogareda, F., Le Strat, Y., Villena, I., De Valk, H., Goulet, V., 20I4. Incidence and prevalence of Toxoplasma gondii infection in women in France, 1980-2020: model-based estimation. Epidemiol. Infect. I42, I66 I-1670. https://doi.org/10.1017/S09502688/3002756 Nuechterlein, K.H., Green, M.F., Kern, R.S., Baade, L.E., Barch, D.M., Cohen, J.D., Essock, S., Fenton, W.S., Frese III, F.J., Gold, J.M., 2008. The MATRICS Consensus Cognitive Battery, part I: test selection, reliability, and validity. Am. J. Psychiatry 165, 203-2I3. Okusaga, O., Duncan, E., Langenberg, P., Brundin, L., Fuchs, D., Groer, M.W., Giegling, I., Stearns-Yoder, K.A., Hartmann, A.M., Konte, B., Friedl, M., Brenner, L.A., Lowry, C.A., Rujescu, D., Postolache, T.T., 2016. Combined Toxoplasma gondii seropositivity and high blood kynurenine--Linked with nonfatal suicidal self-directed violence in patients with schizophrenia. J. Psychiatr. Res. 72, 74-8I. https://doi.org/I0.1016/j.jpsychires.2015.10.002 
Okusaga, O., Langenberg, P., Sleemi, A., Vaswani, D., Giegling, I., Hartmann, A.M., Konte, B., Friedl, M., Groer, M.W., Yolken, R.H., Rujescu, D., Postolache, T.T., 20I I. Toxoplasma gondii antibody titers and history of suicide attempts in patients with schizophrenia.

Schizophr. Res. 133, 150-155. https://doi.org/I0.1016/j.schres.201 I.08.006

Poitrenaud, J., Deweer, B., Kalafat, M., Van der Linden, M., 2007. Adaptation en langue française du California Verbal Learning Test. Paris Éditions Cent. Psychol. Appliquée.

Prandovszky, E., Gaskell, E., Martin, H., Dubey, J.P., Webster, J.P., McConkey, G.A., 201 I. The neurotropic parasite Toxoplasma gondii increases dopamine metabolism. PloS One 6, e23866. https://doi.org/I0.137//journal.pone.0023866

Reitan, R.M., 1958. Validity of the Trail Making Test as an indicator of organic brain damage. Percept. Mot. Skills 8, 27I-276.

Ryan, J.J., Ward, L.C., 1999. Validity, reliability, and standard errors of measurement for two seven-subtest short forms of the Wechsler Adult Intelligence Scale-III. Psychol. Assess. II, 207.

Schürhoff, F., Fond, G., Berna, F., Bulzacka, E., Vilain, J., Capdevielle, D., Misdrahi, D., Leboyer, M., Llorca, P.-M., FondaMental Academic Centers of Expertise for Schizophrenia (FACE-SZ) collaborators, 20I5. A National network of schizophrenia expert centres: An innovative tool to bridge the research-practice gap. Eur. Psychiatry J. Assoc. Eur. Psychiatr. https://doi.org/10.1016/j.eurpsy.2015.05.004

Shehata, A.I., Hassanein, F.I., Abdul-Ghani, R., 2016. Seroprevalence of Toxoplasma gondii infection among patients with non-schizophrenic neurodevelopmental disorders in

Alexandria, Egypt. Acta Trop. 154, I55-159. https://doi.org/I0.1016/j.actatropica.2015.11.016 Sugden, K., Moffitt, T.E., Pinto, L., Poulton, R., Williams, B.S., Caspi, A., 2016. Is Toxoplasma Gondii Infection Related to Brain and Behavior Impairments in Humans? Evidence from a Population-Representative Birth Cohort. PloS One II, e0I48435.

https://doi.org// 0.137//journal.pone.0148435

Sutterland, A.L., Fond, G., Kuin, A., Koeter, M.W.J., Lutter, R., van Gool, T., Yolken, R., Szoke, A., Leboyer, M., de Haan, L., 20I5. Beyond the association. Toxoplasma gondii in schizophrenia, bipolar disorder, and addiction: systematic review and meta-analysis. Acta Psychiatr. Scand. https://doi.org/ I 0.I I I I/acps. 12423

Tao, H., Wong, G.H.Y., Zhang, H., Zhou, Y., Xue, Z., Shan, B., Chen, E.Y.H., Liu, Z., 2015. Grey matter morphological anomalies in the caudate head in first-episode psychosis patients with delusions of reference. Psychiatry Res. 233, 57-63.

https://doi.org/I0.1016/j.pscychresns.2015.04.0I I

Tomasik, J., Schultz, T.L., Kluge, W., Yolken, R.H., Bahn, S., Carruthers, V.B., 20I6. Shared Immune and Repair Markers During Experimental Toxoplasma Chronic Brain Infection and Schizophrenia. Schizophr. Bull. 42, 386-395. https://doi.org// 0.1093/schbul/sbv I 34

Vlatkovic, S., Sagud, M., Svob Strac, D., Sviben, M., Zivkovic, M., Vilibic, M., Vuksan-Cusa, B., Mihaljevic-Peles, A., Pivac, N., 2017. Increased prevalence of Toxoplasma gondii seropositivity in patients with treatment-resistant schizophrenia. Schizophr. Res. https://doi.org/10.1016/j.schres.2017.08.006

Wechsler, D., 2008. Echelle d'intelligence de Wechsler pour adultes: WAIS-III. Les Editions du Centre de Psychologie Appliquée.

Witola, W.H., Liu, S.R., Montpetit, A., Welti, R., Hypolite, M., Roth, M., Zhou, Y., Mui, E., Cesbron-Delauw, M.-F., Fournie, G.J., Cavailles, P., Bisanz, C., Boyer, K., Withers, S., Noble, A.G., Swisher, C.N., Heydemann, P.T., Rabiah, P., Muench, S.P., McLeod, R., 20I4. ALOXI2 in human toxoplasmosis. Infect. Immun. 82, 2670-2679. https://doi.org// 0. I I 28/IAI.0I505-I3 Xiao, J., Li, Y., Gressitt, K.L., He, H., Kannan, G., Schultz, T.L., Svezhova, N., Carruthers, V.B., Pletnikov, M.V., Yolken, R.H., Severance, E.G., 2016. Cerebral complement Clq activation in chronic Toxoplasma infection. Brain. Behav. Immun. 58, 52-56. 
https://doi.org//0.1016/j.bbi.2016.04.009

Xiao, J., Yolken, R.H., 20I5. Strain hypothesis of Toxoplasma gondii infection on the outcome of human diseases. Acta Physiol. Oxf. Engl. 213, 828-845.

https://doi.org/I0.I I I I/apha. 12458 